\title{
Quantified Femtosecond Laser Based Opto-perforation of Living Cells
}

\author{
Judith BAUMGART ${ }^{* 1}$, Willem BINTIG ${ }^{* 2}$, Anaclet NGEZAHAYO*2 ${ }^{* 2}$, Saskia WILLENBROCK ${ }^{* 3}$, Hugo MURUA \\ ESCOBAR $^{* 3}$, Wolfgang ERTMER ${ }^{* 4}$, Holger LUBATSCHOWSKI ${ }^{* 1}$, and Alexander HEISTERKAMP ${ }^{* 1}$ \\ ${ }^{* 1}$ Laser Zentrum Hannover, Hollerithallee 8, Hannover, Germany \\ E-mail: J.baumgart@lzh.de \\ ${ }^{* 2}$ Institute of Biophysics, Leibniz University Hannover, Herrenhaeuserstr. 2, Hannover, Germany \\ ${ }^{* 3}$ Animal Clinic, University of Veterinary Medicine, Bischofsholer Damm 15, Hannover, Germany \\ ${ }^{* 4}$ Institute of Quantum Optics, Leibniz University Hannover, Welfengarten 1, Hannover, Germany
}

\begin{abstract}
Opto-perforation is an interesting alternative to conventional techniques for gene transfer into living cells. The cell membrane is perforated by femtosecond (fs) laser pulses, in order to induce an uptake of macromolecules. In this study, we successfully transfected cells with GFP vector. Transfected cells were not showing any signs of apoptosis or necrosis after $48 \mathrm{~h}$. Based on simultaneously measured membrane potential changes, we calculated and experimentally verified that the relative volume exchanged is 0.4 times the total cell volume. Thus, for the first time quantitative predication of the amount of uptaken molecules and therefore a quantification of transfection is possible.
\end{abstract}

DOI: 10.2961/jlmn.2009.02.0007

Keywords: transfection, femtosecond laser, opto-perforation, membrane potential, patch-clamp

\section{Introduction}

Transfection or introduce particles or molecules into a living cell is an important tool in cell biology to analyse dynamic pathways and the function of cell organelles. Another essential technique is the fluorescence labeling of biological tissue. Autogene or endogene fluorophores typically excited by UV or visible light help to increase the contrast compared to bright field imaging. Therefore exogenous fluorophores have to be introduced into the cells to attach to special proteins or other molecules. Then a single cell organelle can be visualized. However, these fluorophores are mostly toxic so that they are not suitable for life cell imaging.

The development of the plasmids coding for green fluorescent protein (GFP) and its derivatives offered the opportunity to observe living cells that produces the fluorophore itself [1]. The DNA of GFP is impermeable to the cell membrane so that it has to be introduced by a transfection technique. Then the DNA of GFP is expressed in parallel to the endogenous DNA of the transfected cell. The produced fusion protein is therefore tagged with a fluorescent label which allows an imaging of the protein within the cell. Common transfection methods are the use of chemical carriers or electroporation [2,3]. However the critical aspect in cell transfection remains the achieved efficiency, toxicity, and reproducibility depending on the characteristics of the used cells.

According to this, primary cells are difficult to transfect using chemical reagents $[4,5]$. Usage of electroporation might as well be limited because the electro shocks can induce irreversible cell damage to sensitive cells as primary cells and stem cells due to their limited cell population [6].
A less harmful method for the delivery of particles is the perforation of the membrane by fs laser pulses $[7,8]$. Whereas the whole membrane is perforated by the electro shocks during electroporation, the fs laser pulses is focused on a small region of the membrane in the order of one micrometer. Due to the shortness of the laser pulses, there is almost no heating of the irradiated volume because the pulse duration is shorter than the thermal conduction time. The manipulation induced by the pulses is reduced to the focal volume because there is no linear absorption but nonlinear multiphoton absorption $[\mathbf{9 , 1 0 ]}$. The multiphoton absorption can solely occur in the focal volume due to the high photon density. So that the perforation of the cell membrane by the fs laser pulses does not harm the whole cell volume but only a small region of some femto liters [8]. Compared to the electroporation, the number of the manipulated cells is very small but the selectivity is very high.

For all that the optimum parameters in terms of viability of the cells after the treatment and the efficiency are not well known. An important question is the opening time of the created transient pores. That is an important factor in terms of the repair mechanisms of the cell. If the cell damage gets too high, the cell starts apoptosis or necrosis.

In this study we combined the opto-perforation method with the patch-clamp technique to get new insights on the mechanics of fs laser based transfection. The membrane potential change leads to the amount of exchanged intraand extracellular media during perforation and gives an idea of the maximum life time of the induced transient pores. As a well studied cell line for patch-clamp technique, we used GFSHR-17 cells.

Additionally we present a microfluidic setup that leads to an improved number of transfected cells. The cells are 
floating through a micro channel and guided by an optical tweezer for a precise positioning of the cell relative to the fs laser focus.

As proof of principle we opto-perforated adherent canine mammary cells (MTH53a) and transfected them with a non-recombinant GFP vector or a recombinant vector coding for a GFP coupled to the architectural transcription factor HMGB1 (GFP-HMGB1). The fs-laser based transfection resulted in either completely (GFP) or nucleus specific (GFP-HMGB1) fluorescing cells demonstrating the ability of the transfected cells to synthesis and process recombinant proteins. The opto-perforation in the microfluidic setup was proofed by transfection of human nonadherent NB-4 cells with the same non-recombinant GFP vector.

\section{Materials and methods}

The described experiments were realized with a setup consisting of a fs-laser system, microscope including a fluorescence equipment and a patch-clamp assembly. In the following, these elements are explained in detail as well as the cell labeling and the cell culture.

\subsection{Laser system and microscope}

The laser system used in this study is a tunable Ti:sapphire laser (Coherent, Chameleon) which generates ultrashort pulses of $140 \mathrm{fs}$ at a repetition rate of $90 \mathrm{MHz}$. The accessible wavelength range is between $715 \mathrm{~nm}$ to 955 $\mathrm{nm}$ and the maximum pulse energy at $800 \mathrm{~nm}$ is $14 \mathrm{~nJ}$.

The laser beam is guided via a shutter (Thorlabs, $\mathrm{SC10}$ ) and an attenuator to the microscope (PALM microdissection system, Zeiss). The beam enters the tubus directly via a home built reflector cube without passing the UV lamp pathway, so that the fluorescence equipment can be used alternatively. A 0.8-NA NIR water immersion objective (Carl Zeiss AG, Achroplan) focuses the beam into the sample with a theoretical spot size of $600 \mathrm{~nm}$ at a central wavelength of $800 \mathrm{~nm}$. The sample is placed in a chamber with a glass bottom having a thickness of $170 \mu \mathrm{m}$. Successful labeling after laser induced perforation of the cell membrane, the fluorescence is observed by exciting the fluorophores by the UV-lamp of the microscope and visualized by a CCD-camera (fig. 1). For the concentration measurements a EM-CCD camera (Andor Technology, iXon) was integrated into the setup.

To allow the comparison of the different laser parameters as irradiation time and pulse energy, the irradiation time was regulated by a fast shutter between $30 \mathrm{~ms}$ and 60 ms with an accuracy of $1 \mathrm{~ms}$. These parameters were chosen as a compromise between perforation efficiency and cell viability (see section 2.4). The pulse energy was changed by an attenuator consisting of a half waveplate and a polarizing beamsplitter cube. All experiments were realized at a central wavelength of $800 \mathrm{~nm}$.

Additionally, a Nd:YAG (cw) laser (LCS-DLT-322, Laser2000) was coupled into the microscope as an optical tweezer via two cylindric lenses and a beamsplitter. The suspension cells are pumped through a microfluidic channel ( $\mu$ slide, ibidi) by a stepping motor pump (KDS100, kdScientific). The cells are guided into the fs-laser focus by the linefocus of the optical tweezer in terms of targeting the membrane.

The imaging program used for the PALM system includes the connection to the CCD-camera and the manipulation tool for the nitrogen laser (Carl Zeiss AG, PALM), which was used to mark the manipulation area by cutting a rectangle into the glass cover slip. The microscope includes the fluorescence equipment, the UV lamp, the filters for propidium iodide (coupled to DNA) and for GFP and the patch-clamp setup.

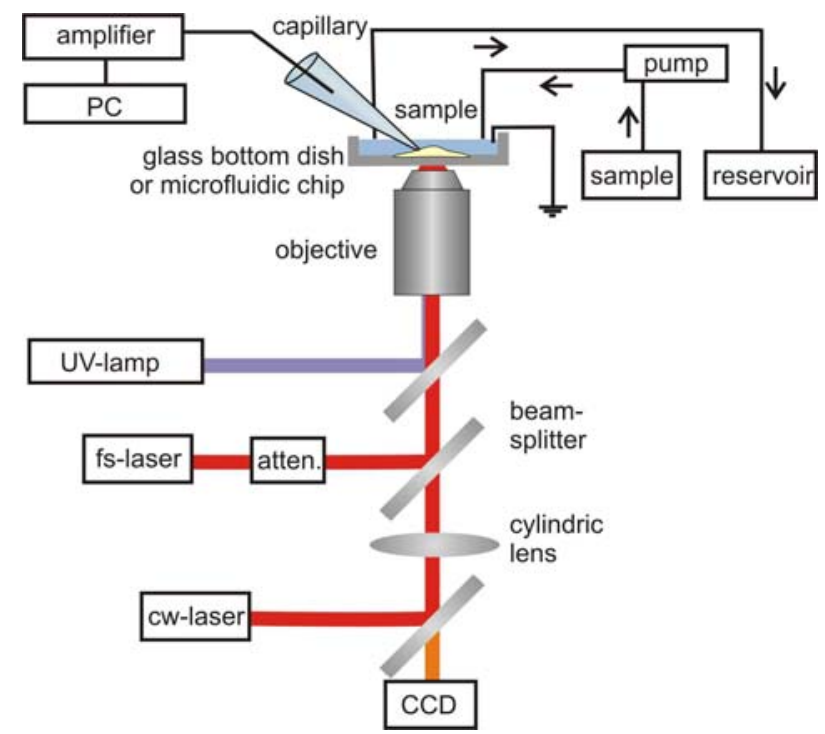

Fig. 1 Microscope setup with patch-clamp equipment.

\subsection{Measurement of the membrane potential}

The membrane potential of the cells was measured by the patch-clamp technique in the current clamp modus [1315] using an amplifier (Axon Instruments, Axopatch-1D) and the computer interface (Instrutech Corporation, ITC-16 Computer Interface) (fig. 1).

The whole cell configuration was established on cells using a pipette solution consisting of $100 \mathrm{mM} \mathrm{K}^{+}$-Gluconat, $40 \mathrm{mM} \mathrm{KCl}, 10 \mathrm{mM}$ Hepes (4-(2-hydroxyethyl)-1piperazineethanesulfonic acid), $5 \mathrm{mM} \mathrm{Na}_{2} \mathrm{ATP}, 1 \mathrm{mM}$ Glucose, $1 \mathrm{mM} \mathrm{MgCl}$, $5 \mathrm{mM}$ EGTA (ethylene glycol tetraacetic acid), $0.25 \mathrm{mM}$ cAMP (3'-5'-cyclic adenosine monophosphate), $0.5 \mathrm{mM}$ cGMP (cyclic guanosine monophosphate), $\mathrm{pH} 7.4$ and an osmolarity $295 \pm 5$. The patch electrode with the pipettesolution has a resistance of $10 \mathrm{M} \Omega$.

The culture media used in the perfusion chamber during the patch-clamp measurements was $\mathrm{NaCl}$-media containing $121 \mathrm{mM} \mathrm{NaCl}, 5 \mathrm{mM} \mathrm{KCl}, 0.8 \mathrm{mM} \mathrm{MgCl}_{2}, 1.8 \mathrm{mM} \mathrm{CaCl}_{2}$, $6 \mathrm{mM} \mathrm{NaHCO} 3,5.5 \mathrm{mM}$ glucose, $25 \mathrm{mM}$ HEPES, pH 7.4 and an osmolarity $295 \pm 5$. 


\subsection{Cells and labeling}

GFSHR-17 granulosa cells of rat were cultivated on cover slips using DMEM 8900 (Dulbecco's Modified Eagle Medium) supplemented with $5 \%$ fetal calf serum (FCS) and the antibiotics penicillin, streptomycin and partricin. For the laser manipulation, a cover slip with cells was transferred in a perfusion chamber containing $0.5 \mathrm{ml}$ of phosphate buffer saline (PBS) and $1.5 \mu \mathrm{M}$ propidium iodide.

The demonstration of the principle of transfection using opto-perforation was performed with pEGFP-C1 or pEGFP-HMGB1 vector to label MTH53a mamma cells of dog. The cells were cultivated on poly-L-lysine coated cover slips using M199 media (Gibco) supplemented with $20 \%$ FCS and penicillin and streptomycin. For the laser treatment, a cover slip with cells was transferred in a perfusion chamber containing $0.5 \mathrm{ml}$ of the culture media and 50 $\mu \mathrm{g} / \mathrm{ml}$ of DNA.

The human NB-4 suspension cells were cultivated in culture flasks using RPMI 1630 (Gibco) media supplemented with $10 \%$ FCS and penicillin and streptomycin. For the opto-perforation the cells were transferred into the microfluidic channel in the media containing $50 \mu \mathrm{g} / \mathrm{ml}$ of the plasmid.

After the fs-laser transfection, the cells were incubated in the media for 24 to 48 hours and then observed by the fluorescence microscope.

\subsection{Opto-perforation and viability control}

Propidium iodide was dissolved in the media before manipulation. The laser was focused onto the membrane of the cell to induce a transient pore and an uptake of the solution with the dye molecules by diffusion. After treatment the cells were observed by fluorescence microscopy to verify the uptake of the dye and then washed with PBS and incubated in PBS for 90 minutes.

Then the viability of the treated cells was controlled by relabeling the sample with propidium iodide and comparing the fluorescence intensity before and after restaining. As the fluorescence intensity of the perforated cells is very low due to the small perforated area and the short interaction time of the laser, there should be an increase of fluorescence intensity in the cells with a damaged cell membrane which indicates the cells to be in a pathologic state.

The DNA transfection was performed in a similar way. The pEGFP-HMGB1 vector was dissolved in the media. To prevent adhesion of the DNA on the glass bottom, the dish was coated with poly-L-lysine. The laser was focused onto the membrane to induce the perforation as in the experiments realized with propidium iodide.

After the treatment, the cells were washed with $\mathrm{NaCl}$ media and then incubated for 48 hours in the culture media. Then the uptake and expression of DNA was verified by fluorescence microscopy.

\subsection{Determination of the exchanged volume during opto-perforation}

Under the present conditions, neither shrinkage nor swelling of the cells were observed during opto-perforation According to the Nernst and Goldman equations (for constant dye-concentration in the media and constant cell volume) the relative exchanged cell volume can be approximated by the following equation [16,17]:

$$
\frac{\alpha}{V}=\frac{1-\exp \left(-\Delta U_{m} F / R T\right)}{1-\exp \left(U_{m} F / R T\right)}
$$

where $\mathrm{V}$ is the cell volume, $\alpha$ the exchanged volume, $\mathrm{R}$ the gas constant, $\mathrm{T}$ the absolute temperature, $\mathrm{F}$ the Faraday constant, $\mathrm{U}_{\mathrm{m}}$ the initial membrane potential and $\Delta \mathrm{U}_{\mathrm{m}}$ the change of membrane potential.

These quantitative considerations can be verified by calibrating the measured fluorescence intensity after treatment. The reference intensities can be determined by introducing a defined lucifer yellow (LY) concentration into the cell via the patch-clamp-pipette in whole-cell configuration. The dye diffuses into the cell and achieves an equilibration with the pipette-solution after 15 minutes. The fluorescence can then be linked to the concentration as a reference intensity. LY is impermeable to the cell membrane and the fluorescence is independent on the binding to any molecules, as for example PI, and is therefore an excellent dye for concentration measurements.

\section{Results}

\subsection{Membrane potential change due to opto- perforation by fs-laser pulses}

One important key factor of the membrane perforation by fs-laser pulses is the exchange of intra and extracellular media so that dye molecules or DNA can diffuse into the perforated cell. During laser perforation of the cell membrane, the media in the immediate vicinity of the pore can enter the cell, a volume of some femtoliters was predicted in literature [8] (fig. 2). Not only molecules, which are meant to diffuse into the cell, are exchanged but also ions as for example sodium or potassium. This alters the membrane potential as the ion concentration inside the cell differs from the concentration in the extracellular media. The verification of the uptake of molecules in these patchclamp experiments was performed with propidium iodide (PI) dissolved in the extracellular media. PI is only fluorescent when bound to DNA. Thus, it is not necessary to wash the sample for the fluorescence observation which could lead to the loss of the whole-cell configuration.

The resting membrane potential of granulosa cells is normally at about $-45 \mathrm{mV}$. Fs-laser irradiation induces depolarization. Depending on the focusing of the laser relative to the membrane, two regimes were found, characterized by the formation or absence of a visible gas bubble. 


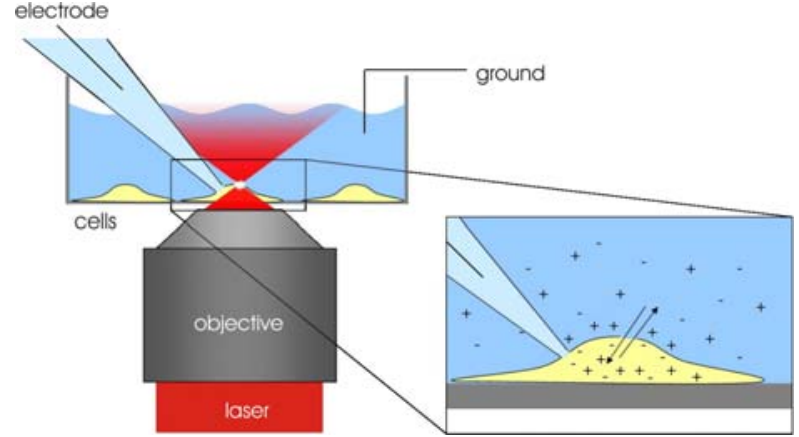

Fig. 2 Principle of membrane potential change due to optoperforation of the cell.

The membrane potential starts to increase about 2 to 5 $\mathrm{mV}$ in both cases (fig 2A). The observed depolarization time $\Delta \mathrm{t}$ is in some milliseconds longer than the laser irradiation time $\mathrm{t}$.

$$
\Delta t>t
$$

While the cases showing no visible formation of the gas bubble were characterized by a slow potential repolarization, the cases showing the gas bubble depolarized dramatically (fig. 3A and 3B). After the manipulation, the potential repolarizes slowly or stays on the new level some $\mathrm{mV}$ above the initial value. In the case of bubble creation the membrane potential starts to depolarize the same way as in the first case. But when the bubble is expanding, the potential increases in general about $10 \mathrm{mV}$ up to $20 \mathrm{mV}$ (fig. 3B). This depolarization continues some ms after the laser irradiation, as in the first case, $\Delta \mathrm{t}>\mathrm{t}$. After that, the cell repolarizes in some cases but slowly compared to the depolarization. In this regime, fluorescence of PI was clearly observable whereas in the case without bubble formation no fluorescence was detectable. Thus, the induced gas bubble can be used as indicator of perforation of the cell membrane and successful uptake of dye molecules.
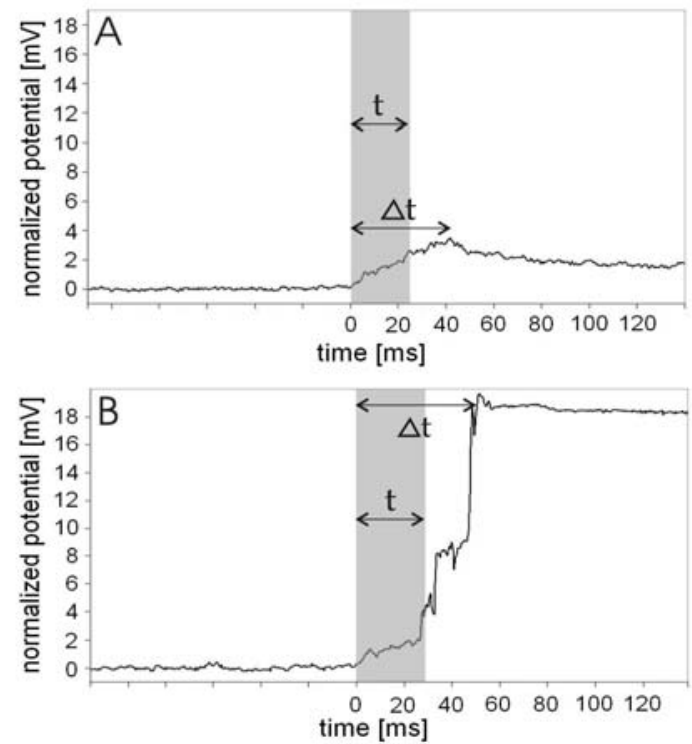

Fig. 3 The membrane potential of a granulosa cell during fs laser perforation [17]. The laser pulse energy was $0.9 \mathrm{~nJ}$. The grey bar represents the laser irradiation time $t$ for the optoperforation, $\Delta t$ represents the maximum depolarization time. (A) There was no bubble formation during the treatment $(\mathrm{n}=7)$; (B) a small gas bubble was created during the treatment $(n=4)$.

\subsection{Determination of the exchanged volume during opto-perforation}

Knowing the membrane potential during laser irradiation, the exchanged cell volume can be calculated. With the mean value of $10 \mathrm{mV}$ membrane potential depolarization, the relative exchanged volume $\alpha / \mathrm{V}$ is about 0.4 . For the GFSHR-17 granulosa cells with a diameter of $10 \mu \mathrm{m}$, measured by trypsinizing the cells and measuring the diameter of the spherical cells, and a volume of 500 femtoliters (fl), the exchanged volume is $200 \mathrm{fl}$. At $200 \mu \mathrm{M}$ dye concentration in the extracellular media, the intracellular dye concentration is about $80 \mu \mathrm{M}$. In the case of a membrane potential depolarization of $3 \mathrm{mV}$, the relative exchanged volume $\alpha / \mathrm{V}$ is 0.13 . For the granulosa cells, the exchanged volume is $65 \mathrm{fl}$ and the intracellular dye concentration is only at $26 \mu \mathrm{M}$.

We performed cell-perforation in presence of different concentrations of LY in the extracellular solution. Since we assumed a relative volume exchange of 0.4 , a dilution of LY by a factor of 2.5 in the cell was expected. The mean fluorescence intensity of the cells after laser-manipulation and after washing with $\mathrm{NaCl}$-media was measured for an extracellular concentration of $1000,600,200$ and $100 \mu \mathrm{M}$ at standard laser parameters, 40ms irradiation time and 0.9 $\mathrm{nJ}$ pulse energy ( 30 to 50 cells per concentration).

The concentration of the LY in the pipette-media was chosen between 2 and $2000 \mu \mathrm{M}$. The fluorescence intensity increases linearly with increasing dye concentration (fig. 4). The measured values fit extraordinarily well to the linear fit. In the case of 2 and $10 \mu \mathrm{M}$ the fluorescence is very low and in most cases not distinguishable from the background. At a concentration of $20 \mu \mathrm{M}$ the fluorescence is more intense and the fluorescent cell clearly observable.

At a LY concentration of $1 \mathrm{mM}$ in the extracellular media the calculation after Eq. 2 results in an intracellular concentration of $400 \mu \mathrm{M}$ after opto-perforation. Following the reference curve for the concentration (fig. 4), we expect a fluorescence intensity of 186 a.u. after perforation. We observed a mean intensity of 142 a.u. which leads to an intracellular concentration of $304 \mu \mathrm{M}$ and a factor of exchanged media $\alpha / \mathrm{V}$ of 0.33 .

For $600 \mu \mathrm{M}$, the mean fluorescence intensity was 123 a.u., the corresponding intracellular concentration is 263 $\mu \mathrm{M}$ (fig. 4) and the factor of exchanged media $\alpha / \mathrm{V}$ of 0.44 . At an extracellular concentration of $200 \mu \mathrm{M}$, the fluorescence intensity was 34 a.u. corresponding to an intracellular concentration of $70 \mu \mathrm{M}$ and an $\alpha / \mathrm{V}$ of 0.35 for the exchanged cell volume. The extracellular concentration of $100 \mu \mathrm{M}$ leads to a factor $\alpha / \mathrm{V}$ of 0.37 at the fluorescence intensity of 19 a.u. and a corresponding intracellular concentration of $37 \mu \mathrm{M}$ (table $\mathbf{1})$. 


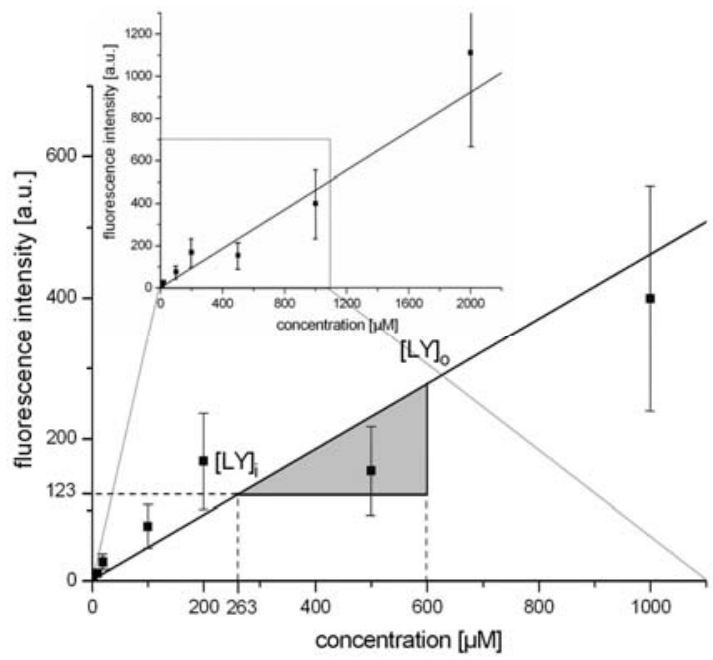

Fig. 4 The fluorescence intensity of LY introduced in cells at different concentrations via the patch-clamp pipette [17]. The data points represent average standard deviation for at least 5 different cells for each concentration. The linear fit $(f(x)=0.46 x+1.77)$ was used to estimate the concentration of LY in the cells after opto-perforation induced uptake of the chromophor dissolved in the extracellular solution. The area of interest for the used extracellular concentrations during opto-perforation is zoomed out. As an example, to the extracellular LY concentration ([LY]o) of $600 \mu \mathrm{M}$ corresponds an intracellular concentration ([LY]i) of 263 $\mu \mathrm{M}$ and a fluorescence intensity of 123 a.u. (table 3.2) represented by the grey triangle.

\begin{tabular}{|c|c|c|c|c|}
\hline $\begin{array}{c}\text { extra- } \\
\text { cellular } \\
\text { concen- } \\
\text { tration } \\
\left([\mathrm{LY}]_{\mathrm{o}}\right) \\
{[\mu \mathrm{M}]}\end{array}$ & $\begin{array}{c}\text { expected } \\
\text { intracellu- } \\
\text { lar con- } \\
\text { centration } \\
{[\mu \mathrm{M}]} \\
(\text { with } \\
\alpha / \mathrm{V}=0.4)\end{array}$ & $\begin{array}{c}\text { measured } \\
\text { intracellular } \\
\text { concentra- } \\
\text { tion }\left([\mathrm{LY}]_{i}\right) \\
{[\mu \mathrm{M}](\text { lin- }} \\
\text { ear fit })\end{array}$ & $\begin{array}{c}\text { measured } \\
\text { fluores- } \\
\text { cence } \\
\text { intensity } \\
{[\text { a.u. }]}\end{array}$ & $\begin{array}{c}\text { relative ex- } \\
\text { changed } \\
\text { volume } \alpha / \mathrm{V} \\
\left([\mathrm{LY}]_{\mathrm{i}} /[\mathrm{LY}]_{\mathrm{o}}\right)\end{array}$ \\
\hline 1,000 & 400 & $304 \pm 91$ & $142 \pm 30$ & $0.33 \pm 0.10$ \\
\hline 600 & 240 & $263 \pm 79$ & $123 \pm 37$ & $0.44 \pm 0.13$ \\
\hline 200 & 80 & $70 \pm 21$ & $34 \pm 12$ & $0.35 \pm 0.10$ \\
\hline 100 & 40 & $37 \pm 11$ & $19 \pm 6$ & $0.37 \pm 0.11$ \\
\hline
\end{tabular}

Tab. 1 Fluorescence intensity of LY measured in cells after application of opto-perforation in presence of different LY concentrations in the extracellular solution ([LY]o) [17]. The values were reported on the calibration line (Fig. 4) to estimate the intracellular LY concentration ([LY]i). The measured relative volume exchanged is given as $[\mathrm{LY}] \mathrm{i} /[\mathrm{LY}] \mathrm{o}$. The expected intracellular concentrations were calculated by assuming $\alpha / \mathrm{V}=$ 0.4 . These values were reported to the calibration curve to obtain the expected fluorescence intensities. All measured values include \pm standard deviation

\subsection{Transfection of adherent or suspension cells by fs- laser pulses with pEGFP-C1 or PEGFP-HMGB1 vectors}

The adherent canine mammary cells (MTH53a) were transfected by opto-perforation applying $40 \mathrm{~ms}$ irradiation time and thus 3.6 million pulses at an energy per pulse of $0.9 \mathrm{~nJ}$. The cells were treated either in presence of 50 $\mu \mathrm{g} / \mathrm{ml}$ non-recombinant $\mathrm{pEGFP-C1}$ vector or recombinant pEGFP-HMGB1 vector in the culture media. The fluorescence was observed 24 and $48 \mathrm{~h}$ after treatment allowing an expression and processing of the respective recombinant proteins. The cells transfected with pEGFP-C1 vector showed a labeling of the complete cell (fig. 5A) by the synthesized recombinant GFP proteins. The cells transfected with the pEGFP-HMGB1 vector showed a specific labeling of the nucleus (fig. 5B). These specific labeling shows that the cells are post transfected still able to synthesize the pEGFP-HMGB1 fusion protein and to transport the chromatin associated architectural transcription factor HMGB1 to its native cellular localization in the nucleus.
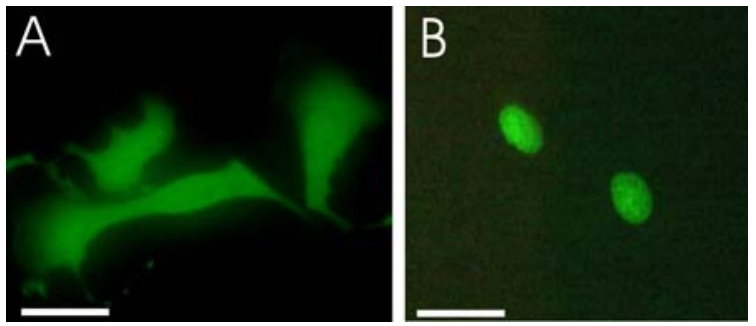

Fig. 5 MTH53a cells transfected with either pEGFP-C1 or pEGFP-HMGB1 vectors. (A) Complete labelling of MTH53a cells by GFP. (B) Specific labelling of the MTH53a cell nucleus by pEGFP-C1-HMGB1 fusion proteins. The opto-perforation was performed at a wavelength of $800 \mathrm{~nm}$, a pulse energy of 0.9 $\mathrm{nJ}$ and an irradiation time of $40 \mathrm{~ms}$. The images were taken 48 hours after the treatment. Scale bars: $20 \mu \mathrm{m}$.

Compared to the transfection of adherent cells, a lower pulse energy was necessary to transfect the suspension NB4 cells. The opto-perforation was performed at $20 \mathrm{~ms}$ irradiation time and $0.7 \mathrm{~nJ}$ pulse energy. As a proof of principle experiment, the cells were manipulated in presence of 50 $\mu \mathrm{g} / \mathrm{ml}$ of pEGFP-C1. Approximately $10 \%$ of the manipulated cells were successfully transfected $(n \approx 300)$.
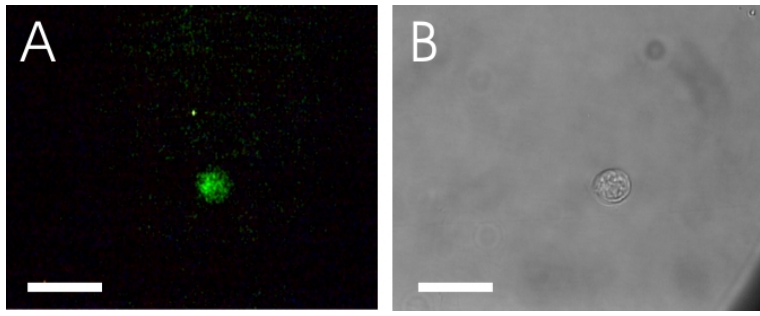

Fig. 6 Transfected NB-4 cell with non-recombinant pEGFP-C1 vector. (A) Fluorescence image of the transfected cell, (B) bright field image of the same cell. The opto-perforation was performed at an exposure time of $20 \mathrm{~ms}$ and a pulse energy of $0.7 \mathrm{~nJ}$. The images were taken 48 hours after the treatment. Scale bars: $20 \mu \mathrm{m}$.

\section{Discussion}

Transfection of macromolecules represents a key technique in molecular biology. The currently applied methods e.g. viral vectors, chemical carriers, lipofection and electroporation face several critical problems in terms of the achieved efficiency, toxicity, and reproducibility. Although for multiple applications the used systems are sufficient, several experimental approaches require more sophisticated methods. Parameters like a defined amount of induced molecule uptake, reduced cell damage and high transfection efficiency represent critical magnitudes when working with cell type requiring extremely high complexity handling e.g. stem cells. The here used fs-laser based optoperforation of cells allows a defined control of the described critical parameters. In detail the measurements of the cell membrane potential showed two different behaviors during opto-perforation. 
As described previously the membrane potential increased in both cases instantaneously about 2 to $5 \mathrm{mV}$ at all parameters. If no bubble was created fluorescence analysis using PI did not show an uptake of the fluorophore in contrast to the case of bubble formation showing a characteristic high PI uptake. The observed difference is probably caused by a disruption or non-disruption of the membrane which is large enough for the uptake of the PI molecules. The critical parameters for formation or non-formation of gas bubbles where shown to be the irradiation time, the pulse energy, and the position of the laser focus relatively to the membrane.

In the case of bubble formation, the potential depolarized first as described above and, as soon as the bubble was created, the potential increased by another $10 \mathrm{mV}$ or more. After the manipulation, the membrane potential repolarized again or stayed at the same level but did not rise to $0 \mathrm{mV}$ in most cases. These results show that there was an exchange of intra and extracellular media, especially when a bubble was induced which can be used as an indicator for successful opto-perforation. Additionally it can be concluded that the cell is still alive and it is able to repair the laser induced damage.

The maximum depolarization time $(\Delta \mathrm{t}=60 \mathrm{~ms})$ is longer than the irradiation time $(\mathrm{t}=30 \mathrm{~ms})$. Thus the induced pore seems to be open longer than the laser irradiation time t. However, it is possible that the pore closes before the depolarization stops. The signal may continue to increase, for example, due to the diffusion of the liquid inside the cell and the time delay the liquid needs to distribute homogeneously in the cell volume.

The volume of exchanged cell media during optoperforation was calculated to be about 0.4 times the cell volume. The comparison of the fluorescence intensities of the introduced dye molecules during laser irradiation of the defined dye concentration after the whole cell patch-clamp verifies this result. In case of $1 \mathrm{mM} \mathrm{LY}$ in the media, the concentration in the perforated cells is $304 \mu \mathrm{M}$ which means a volume exchange of 0.33 times the cell volume. At an extracellular concentration of $600 \mu \mathrm{M}$ the relative exchanged volume is 0.44 , at $200 \mu \mathrm{M}$ it is 0.35 and at 100 $\mu \mathrm{M}$ it is 0.37 . Therefore, our calculations are in very good agreement with the experimental data and enable us to estimate how many molecules are taken up during optoperforation.

We successfully transfected canine mamma cells with non-recombinant pEGFP-C1 vector or recombinant pEGFP-C1-HMGB1 vector. This specific labeling shows that the fs-laser based transfection allows even to successfully transfect cells which are still able to synthesize and process recombinant proteins. The calculation of the exchanged cell volume gives information about the number of introduced DNA molecules. At an extracellular concentration of the pEGFP-HMGB1 vector of $50 \mu \mathrm{g} / \mu \mathrm{l}$, about $10 \mathrm{fg}$ DNA molecules enter into the perforated cells during laser irradiation at a cell diameter of $10 \mu \mathrm{m}$, if the membrane potential change during perforation is about $10 \mathrm{mV}$ (as measured for the GFSHR-17 granulosa cells). The effi- ciency of introduction and the viability of the treated cells strongly depend on the laser parameters and the position of the laser focus relative to the cell membrane.

The transfection of suspension NB-4 cells was successfully performed in the microfluidic chamber using the Nd:YAG laser as optical positioning of the cells. The laser parameters used were $0.7 \mathrm{~nJ}$ pulse energy and $20 \mathrm{~ms}$ irradiation time which is lower and shorter than for adherent cells. This is probably due to the fact that adherent cells are very flat growing on the cover glass of the dishes whereas the suspension cells are spherical and targeting the edge of the cell is therefore more precise when using bright field microscopy. The optimum laser and flow parameters have to be investigated for high transfection efficiency. The efficiency in the described proof of principle experiments was approximately $10 \%$. The automation of transfection due to this microfluidic setup offers the possibility of high throughput perforation. This is required for most of the applications in biology and medicine for adequate numbers of transfected cells.

Finally, the established system allows a controlled transfection of cells including the possibility to determine the amount of transfection uptake and thus allowing to regulate the amount of effector molecules transfected into the cell. Consequently this allows a gentle procedure for e.g. stem cell transfection opening new possibilities for stem cell based experimental and therapeutic approaches.

\section{Acknowledgment}

We would like to acknowledge Prof. Bernhard Keller (GeorgAugust University, Goettingen) for placing the patch-clamp setup to our disposal and BFI optilas for providing the EM-CCD camera. Parts of this work were funded by the German Research Foundation (DFG) within the Transregio 37 and the excellence cluster REBIRTH.

\section{References}

[1] Chalfie, M., Tu, Y., Euskirchen, G., Ward, W.W., Prasher, D.C., Science, 263 (5148), 802-805 (1994)

[2] Prasher, D.C., Eckenrode, V.K., Ward, W.W., Prendergast, F.G., Cormier, M.J., Gene, 111, 229-233 (1992)

[3] Tekle, E., Astumian, R.D., Chock, P.B., Proc. Natl. Acad. Sci. USA, 88, 4230-4234 (1991)

[4] Stilwell, J.L., McCarty, D.M., Negishi, A., Superfine, R., Samulski, R.J., J. Virol., 12881-12885 (2003)

[5] Wold, W.S., Doronin, K., Toth, K., Kuppuswamy M., Lichtenstein, D.L., Tollefson A.E., Curr. Opin. Immunol., 11, 380--386 (1999)

[6] Menendez, P., Wang, L., Bhatia, M., Curr. Gene Ther., 5, 375-385 (2005)

[7] Tirlapur, U.K., König, K., Nature, 418, 290-291 (2002)

[8] Stevenson, D. et al., Optics Express, 14(16), 71257133 (2006), http://www.opticsexpress.org/abstract.cfm?uri=OE14-16-7125

[9] Denk, W., Strickler, J.H., Webb, W.W., Science, 248, 73-76 (1990) 
[10] König, K., Riemann, I., Fischer, P., Halbhuber, K.J., Cell. Moll. Biol. 45, 195-201 (1999)

[11] Kohli, V., Acker, J.P., Elezzabi, A.Y., Biotechnol. Bioeng., 92, 7 (2005)

[12] Vogel, A., Venugopalan, V., Chem. Rev., 103, $577-$ 644 (2003)

[13] Hamill, O.P., Marty, A., Neher, E., Sakmann, B., Sigworth, F.J., Pflügers Arch., 391, 85-100 (1981)
[14] Neher, E., Sakmann, B., Nature, 260, 799-802 (1976)

[15] Numberger, M., Draguhn, A., "Patch-ClampTechnik“ (Spektrum Akademischer Verlag, 1996)

[16] Goldman, D., J. Gen. Physiol., 27, 37-60 (1943)

[17] Baumgart, J., Bintig, W., Ngezahayo, A., Willenbrock, S., Murua Escobar, H., Ertmer, W., Lubatschowski, H., Heisterkamp, A., Optics Express, 16, 3021-3031 (2008)

(Received: July 4, 2008, Accepted: June 5 , 2009) 